\title{
Changes in the Moisture Content, Free FFA and Malondialdehyde of Bajra Flour during Storage
}

\author{
V.M. Bhatt ${ }^{1}$, M.N. Dabhi ${ }^{2}$, P.J. Rathod ${ }^{3}$ \\ ${ }^{1}$ Associate Research Scientist, AGRISNET, Junagadh Agricultural University, Junagadh \\ ${ }^{2}$ Research Engineer AICRP on Post Harvest Engineering and Technology, Department of Processing and Food \\ Engineering, College of Agril. Engg. \& Technology, JAU, Junagadh \\ ${ }^{3}$ Assistant Professor, Department of Biochemistry \& Biotechnology, Junagadh Agricultural University, Junagadh- \\ 362001(Gujarat) India \\ Email: mndabhi@jau.in
}

\begin{abstract}
Experiments were conducted to assess a storage of bajra flour of five cultivars viz GHB538, GHB-558, GHB-732, GHB-744, Desi(V) with different packaging materials of Tin container(C1), HDPE container(C2), Cotton bag $(\mathrm{C} 3)$, LDPE bag $(\mathrm{C} 4)$ at room temperature $\left(\mathrm{T} 1: 37^{\circ} \mathrm{C}\right)$ and at low temperature (T2:refrigerator) for 16 days. The best storage condition to enhance the keeping quality of flour of Bajra varieties with effect of storage containers and temperature on biochemical quality parameters of Bajra flour was analyzed. The increase in moisture content (1.85\%) was higher in Desi Variety flour at room temperature in cotton bag. The increase in FFA (3.35\%) was higher in GHB558 variety flour at room temperature in cotton bag. The increase in Malondialdehyde was higher in GHB-538 as well as GHB-558 flour stored in cotton bag at room temperature. The increased values of all parameters were found in flour stored in tin container and plastic container at low temperature.
\end{abstract}

Keywords: Bajra flour; storage; FFA; malondialdehyde

\section{Introduction}

Bajra (Pearl millet) has the largest seeds and is the most widely grown millet [9]. Millet cannot store in the form of flour, but the cause of the instability is not known. No change was found in the amino acid composition during storage, but the total fatty acids showed significant quantitative changes in composition [4]. They attribute those changes to hydrolytic decomposition of lipids and, to a lesser extent, to oxidation.

On the other hand, it was found that the majority of volatile compounds emitted during storage were alcohols, indicating that fermentation was occurring [16]. At the same time, hydrolytic action of lipases appeared to increase with increases in meal moisture. Ultraviolet (UV) spectrophotometry of lipid extracts produced no evidence of oxidation of the unsaturated fatty acids. Till today, bajra flour is prepared in limited quantity by women for immediate needs.

Millet is probably the cereal grain that most rapidly develops objectionable odours and flavours after converting into flour. This may be due to high fat content, higher unsaturation of fatty acids, lacking in antioxidants occurring naturally or greater enzymatic activity. But studies on fatty acid composition of pearl millet indicate that pearl millet lipids tend to be higher saturated fatty acids and lower in unsaturated fatty acids as compared to other cereals $[10,12,15]$. The measurement of lipoxygenase activity and the UV spectrophotometry of the lipoidal extracts led [16] to the conclusion that the enzymatic oxidation of lipids was practically nonexistent. He also argued that present of phenolic compounds acted as antioxidants. Hence, only high fat content is the only reason for odd flavours of bajra flour. Millet grains, before consumption and for preparing of food, are usually processed by commonly used traditional processing techniques including decorticating, malting, fermentation, roasting, flaking, and grinding to improve their edible, nutritional, and sensory properties. However, negative changes in these properties during processing are not avoidable because industrial methods for processing of millets are not as well developed as the methods used for processing of wheat and rice [7]. 
Varietal differences of bajra have modified nutritional quality. There may be difference in quality of flour after grinding. It is also important to check the varietal effect on storage quality of flour. Millet Research Centre, Jamnagar is working on different variety of millet. Hence, it is necessary to carry out the research on varietal effect on storage of bajra flour in different container at different temperature.

The aim of our study was to store bajra flour in different container and to analyses the data for the most suitable ones for qualitative traits for storage. The experiment is framed to study the storage life of bajra flour which is very less as compared to other major cereals. The study has widespread applicability and concern to consumers.

\section{Materials and Methods}

Five Bajra varieties [GHB-538(V1), GHB-558(V2), GHB-732(V3), GHB-744(V4), Desi(V5)] collected from Millet Research Station, JAU, Jamnagar and bajra flours of each variety were prepared in grinder. The bajra flour was filled into Tin container(C1), HDPE container(C2), Cotton bag(C3), LDPE bag(C4) at Room temperature, $\sim 37^{\circ} \mathrm{C}(\mathrm{T} 1)$ and Low temperature $(\mathrm{T} 2), 10 \pm 2^{\circ} \mathrm{C}$ (refrigerator). The observations have been recorded at four days interval. Total storage period was 16 days.

Moisture was determined by [1] method No. 44-19 and fat acidity was determined by adopting procedure described in [2] method No. (940.22). Two grams of bajra sample was placed in preheated and weighed petri dish and dried in an oven at $120^{\circ} \mathrm{C}$ for 3 hours or till constant weight. The loss in weight was calculated as percentage of moisture content of flour. Fats extracted from 10 grams of flour with hexane were dissolved in $50 \mathrm{ml}$ of $0.02 \%$ solution of phenolphthalein in toluene and ethanol (1:1), titrated with 0.0178 molar solution of potassium hydroxide. The result was reported as milligrams of potassium hydroxide used per 100 grams of flour and Melonaldehyde were statistically analyzed with CRD. All parameters were determined in triplicate for each flour sample from initial to 16 days at interval of 4 days.

\section{1 $\quad$ Statistical Analysis}

The Moisture content, free FFA and Melonaldehyde data obtained was analyzed statistically to determine statistical significance of treatments. Completely Randomized Design (CRD) was used to test the significance of results [13]. The analysis of variance revealed at significance of $\mathrm{p}<0.05$ level, S.E. and C.D. at $5 \%$ level was mentioned wherever required.

\section{$3 \quad$ Results and Discussions}

\subsection{Moisture Content}

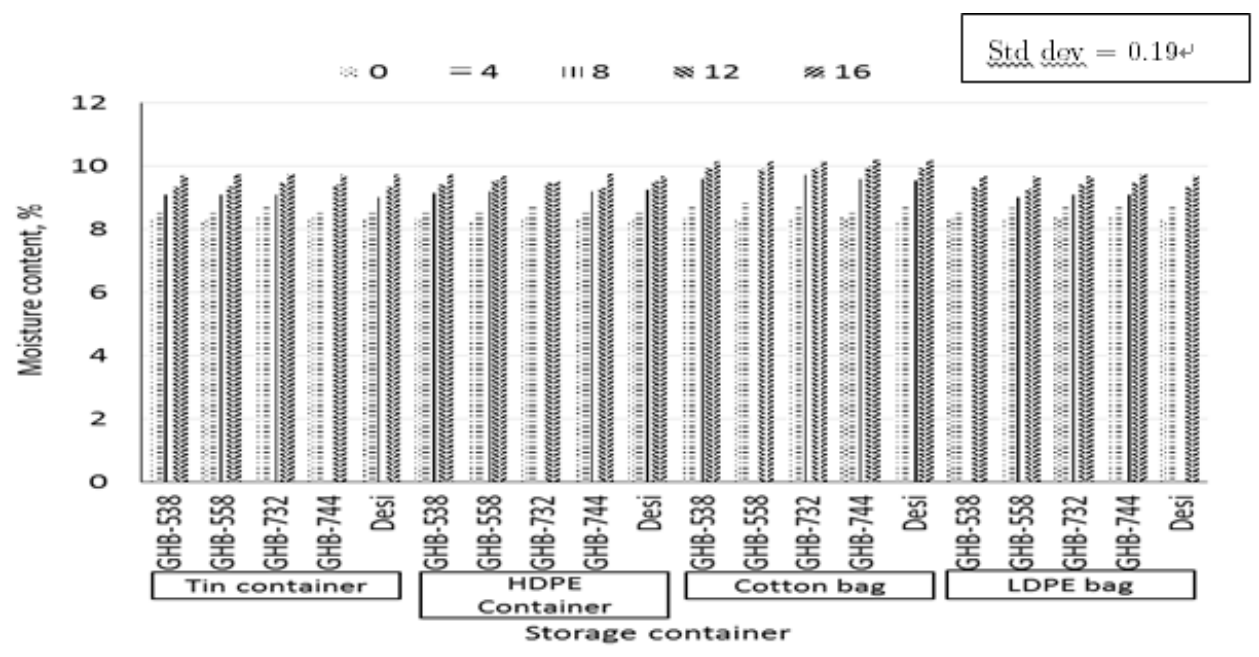

Figure 1. Effect of storage container and storage days on Moisture content at room temperature 


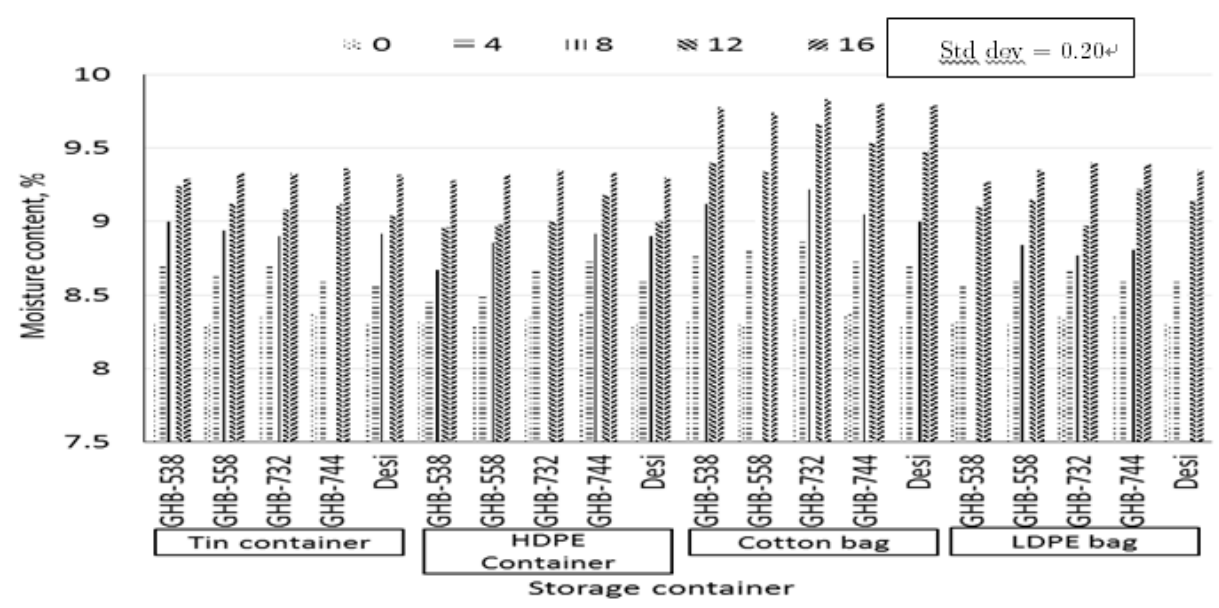

Figure 2. Effect of storage container and storage days on Moisture content at low temperature

The moisture content of any product is important for the shelf life. Generally moisture content decreases or increases during storage depending upon the storage condition and packaging material. In this experiment the data revealed that moisture percent of bajra flour was found significant after 16 days of storage. Increasing trend can be found in treatment of all the varieties of bajra flour kept in cotton bag and stored at room temperature (Fig. 1). Similar effect of packaging was also found at low temperature (Fig. 2). The minimum value of moisture content was found in the treatment HDPE container and tin container for all varieties at low temperature. Thus, it may be concluded that tin container and HDPE container are better for all varieties stored at low temperature. According to varietal difference initial higher moisture content was found in GHB-744 variety but change in moisture content after 16 days was minimum in tin container at low temperature whereas in the desi variety initial moisture content was low but after 16 days storage in cotton bag the change in moisture content was more. For all varieties, cotton bag was found more susceptible for moisture gain in bajra flour. The results are supported by authors [11]. They found that the initial moisture content of the millet flour was $9.5 \%$ which increased after storage period of 112 days up to $9.8 \%$ in cotton bags.

\subsection{Free Fatty Acids}

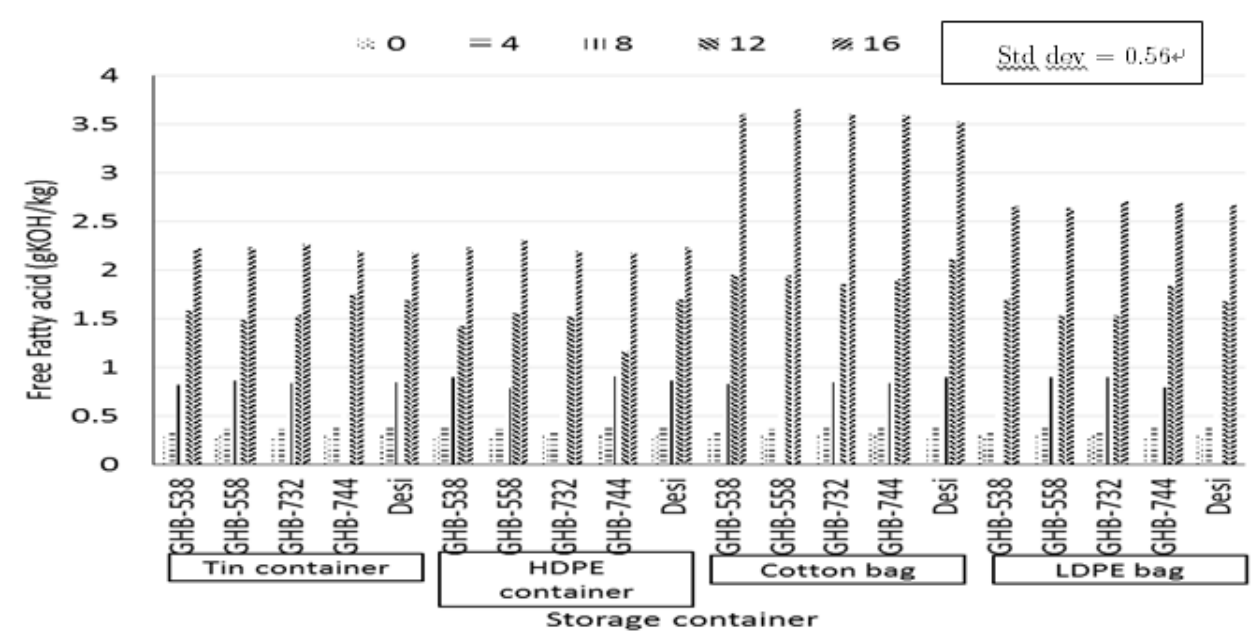

Figure 3. Effect of storage container and storage days on Free Fatty Acid at room temperature 


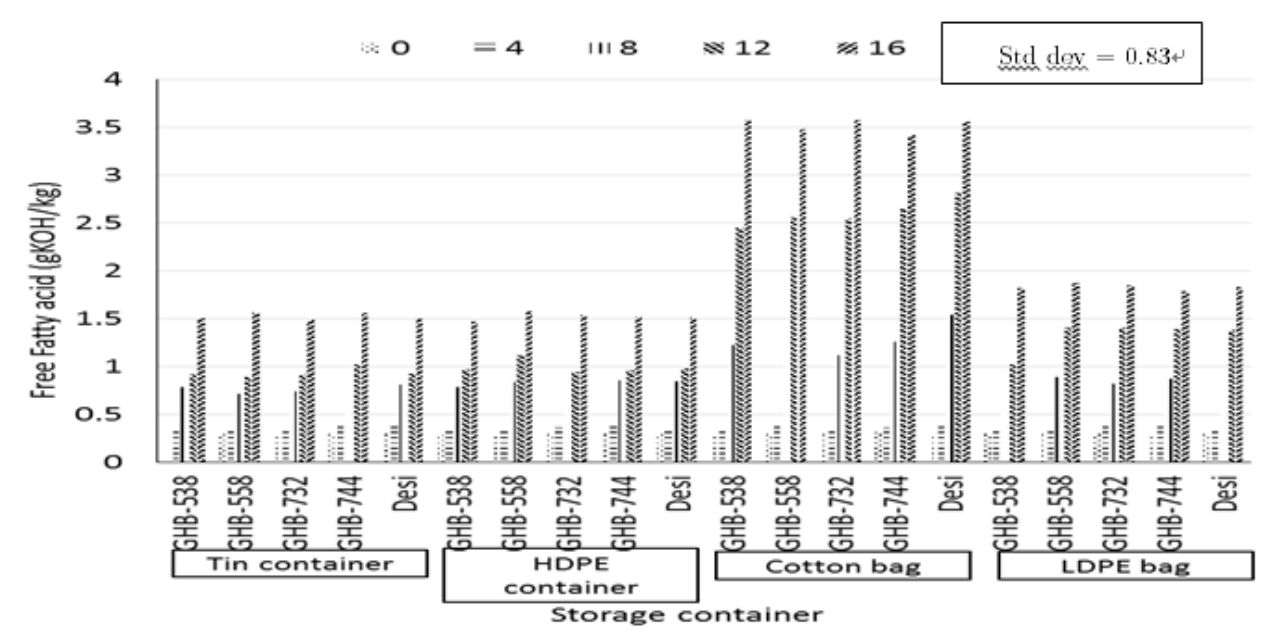

Figure 4. Effect of storage container and storage days on Free Fatty Acid at low temperature

Free fatty acid is an important parameter for storage of bajra flour. FFA was found significant after 16 days of storage (Fig. 3\&4). The maximum in the treatments of cotton bag for both temperatures was found. It means the cotton bag produced more FFA content as compared to the material packaging. The minimum value of FFA was observed in the treatment of tin container and HDPE bag at low temperature. Looking to the above results thin container and HDPE containers are better storage material at low temperature for all varieties. It was also found that GHB-744 variety has the highest initial fatty acid but after 16 days of storage in cotton bag the highest free fatty acid was reported in GHB-558 variety at room temperature and after the storage period of 16 days the lowest change in free fatty acid was found in GHB-538 variety at low temperature. Similar results found in an experiment that millet flour stored at $27^{\circ} \mathrm{C}$ in cotton and plastic bags; fat acidity increased at different rates for samples stored in both plastic and in cotton bags [11]. The fatty acid increased more rapidly in the sample stored in the cotton bags, presumably because of the higher moisture level for those samples. The hydrolytic action of lipases, as measured by fat acidity, is known to be more rapid at higher moisture levels.

The overall results for FFA are an increase throughout storage of samples stored either in plastic or cotton bags. Because the TFA for samples did not change and the FFA increased, it appears that hydrolytic action of lipases is predominant. The proportion of free fatty acids released was similar to those found in the total fatty acids, so lipase action was probably random.

\subsection{Malondialdehyde Value}

Malondialdehyde is a highly reactive compound that is not typically observed in pure form. Malondialdehyde results from lipid peroxidation of polyunsaturated fatty acids [6]. The Thiobarbituric acid (TBA) test has been widely used as an objective measure of secondary oxidation products of oils. It relates to the level of malondialdehyde formed during oxidation of lipids. It is assumed that accumulation of these products is responsible for the development of rancid odours and off-flavour of the oil [8]. Malondialdehyde, formed from the breakdown of polyunsaturated fatty acids, serves as a convenient index for determining the extent of the peroxidation reaction [8]. Malondialdehyde has been identified as the product of lipid peroxidation that reacts with thiobarbituric acid to give a red species absorbing at $535 \mathrm{~nm}[3]$.

It was found that Malondialdehyde value of bajra flour was significant and increasing during storage period. The maximum value recorded in the treatment of cotton bag for ambient condition, followed by cotton bag for low temperature condition for all the varieties. Whereas the minimum value was found in the treatments of tin container for ambient condition, followed by HDPE bag for low temperature condition for all the varieties. Thus it is concluded that tin and HDPE (plastic) container were good for all the varieties stored at low temperature as minimum increase in Malondialdehyde value. The highest initial Malondialdehyde value was found in GHB-744 variety but after the storage period of 16 days the 
highest change in Malondialdehyde value was reported in GHB-538 and GHB-558 variety in cotton bag at room temperature and the lowest change in Malondialdehyde was reported in GHB-558 variety in HDPE container at low temperature. These results are in agreement with others who studied whole grain flour of 3 varieties of pearl millet (Pennisetum typhoides), which became rancid on days $6,7,8$ and 10, and inedible on days 11, 12, 13 and 14 of storage in gunny sacks, earthen pots, tin cans and polythene bags, respectively [5]. The moisture, sugar, free fatty acids, fat acidity and peroxide values increased, and flour stored in polythene bags was the least affected and that stored in gunny sacks was the most affected by storage conditions. The flour moisture content was found highly variable indicating variable moisture holding capacity of flour. This was also reported in cereals and pulses [14]. The peroxide values for samples stored in plastic bags showed a different pattern than values for samples stored in cotton bags. In plastic bags, the peroxide value increased up to 5.1 meq peroxide value per kilogram of fat after $62 \mathrm{hr}$ of storage and then decreased to near its original value. The peroxide value of millet flour stored in cotton bags remained constant throughout the storage period [11].

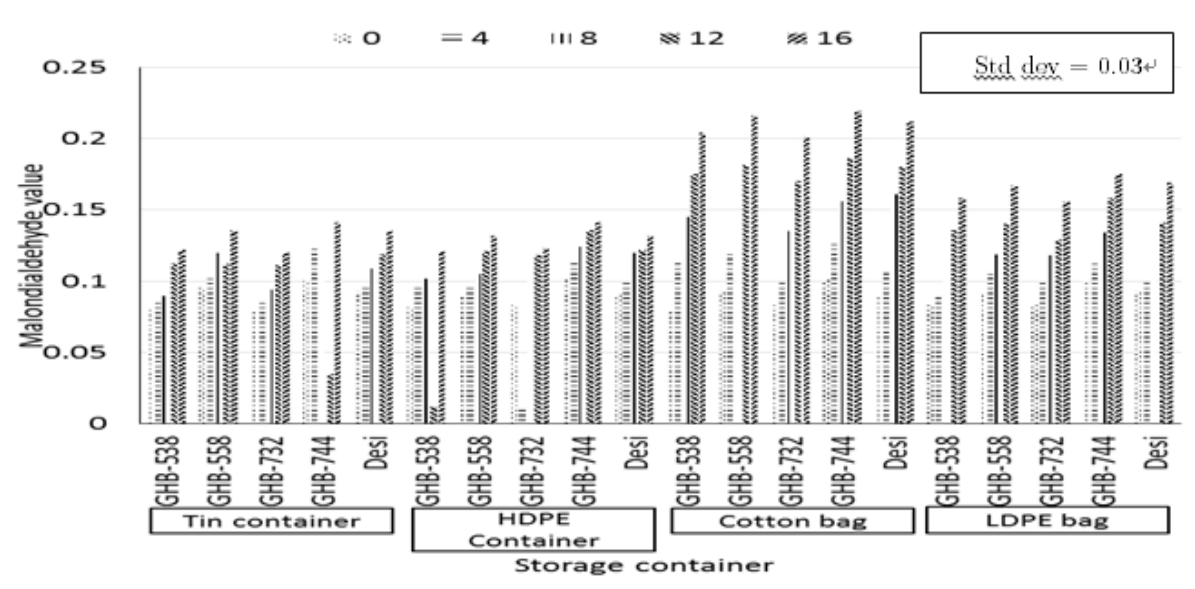

Figure 5. Effect of storage container and storage days on Malondialdehyde at room temperature

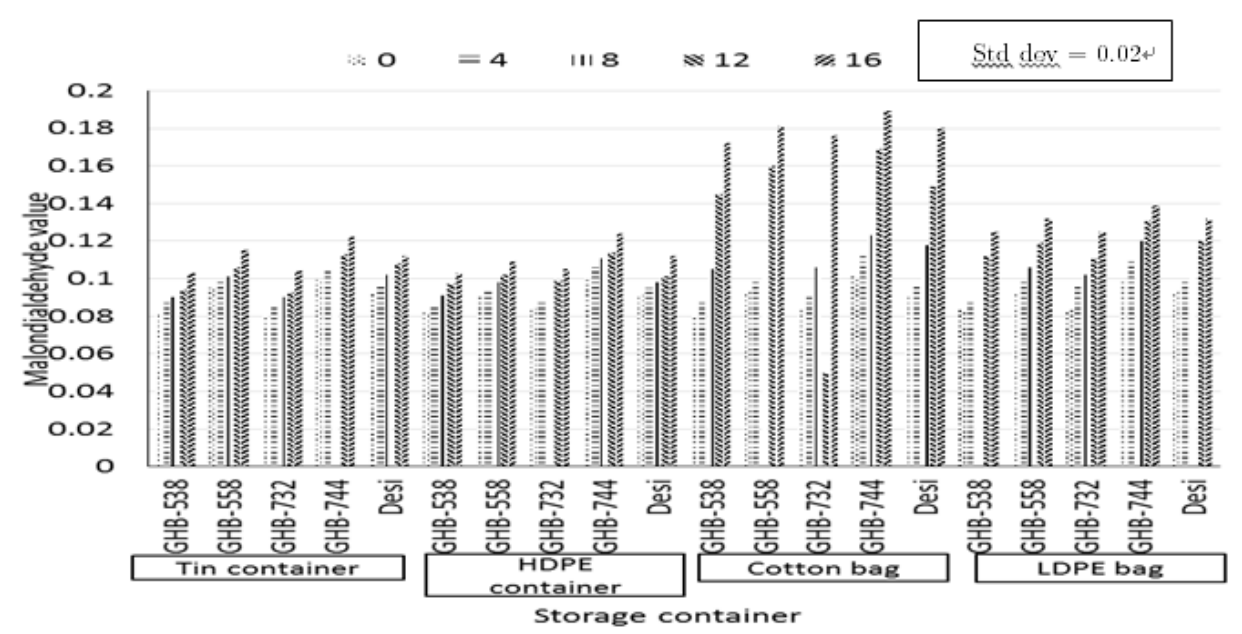

Figure 6. Effect of storage container and storage days on Malondialdehyde at low temperature

\section{Conclusion}

It can be concluded that GHB-558 variety is suitable to store up to 16 days in the form of flour at low temperature for the least change in moisture content, free fatty acid and malondialdehyde. Tin and 
HDPE container are suitable for storage of bajra flour. Cotton bag is not suitable for storage of bajra flour. Desi variety millet is not suitable for storage in the form of flour.

Acknowledgments. The authors acknowledge the financial support from All India Coordinated Research Project on Post-Harvest Engineering and Technology.

\section{References}

1. AACC. (2002). Approved Methods of American Association of Cereal Chemists. Amer. Assoc. of Cereal Chemists. Inc., St. Paul, Minnesota, USA.

2. AOAC. (2005). Official Methods of Analysis. Assoc. of Official Analyt. Chemists, Virginia, USA.

3. Antonio Ayala, Mario F. Muñoz, and Sandro Argüelles, Lipid Peroxidation: Production, Metabolism, and Signaling Mechanisms of Malondialdehyde and 4-Hydroxy-2-Nonenal. http://dx.doi.org/10.1155/2014/360438. Page 31 (2014).

4. Carnovale, E., and Quaglia, G. B, Influence of temperature and humidity controlled preservation on the chemical composition of milling products from millet. Ann. Technol. Agric. 22:371 (1973).

5. Chaudhary, P. and Kapoor, A.C, Changes in the nutritional value of pearl millet flour during storage. Journal of the Science of Food and Agriculture, 35 (11). pp. 1219-1224 (1984).

6. Draper, H.H. and M. Hadley, Oxygen Radicals in Biological Systems Part B: Oxygen Radicals and Antioxidants in Methods in Enzymology. 186:421-431(1990).

7. FAO (Food and Agriculture Organization). Economic and Social department: The Statistical Division. Statisticas Division 2012. Available from FAO [http://faostat.fao.org/site/567/DesktopDefault.aspx?PageID=567\#ancor]. Posted September 29 (2012).

8. Gaweł S, Wardas M, Niedworok E, Wardas P. Malondialdehyde (MDA) as a lipid peroxidation marker. Wiad Lek. 57(9-10):453-455(2004).

9. Hoseney, R. C., Varriano-Marston, E., and Dendy, D.A.V, Sorghum and millets. Page 71 in: Advances in Cereal Science and Technology. Vol. IV. Y. Pomeranz. ed. Am. Assoc. Cereal Chem., St. Paul, M. N. (1982)

10.Jellum, M. D., and Powell, J. B, Fatty acid composition of oil from pearl millet. Agron. J. $63: 29$ (1971).

11.Kased, I.; R. C. Hoseney; E. Varriano-Marston, Factors affecting rancidity in ground pearl millet (Pennisetum americanum L. Leeke). Cereal Chem. 61(2):187-192 (1984).

12.Lai, C. C., and Varriano-Marston, E. Lipid content and fatty acid composition on free and bound lipids in pearl millets. Cereal Chem. 57:271 (1980)

13.Panse V. S. and Sukhatme P. V, Statistical Methods for Agricultural Workers. Indian Council of Agricultural Research. New Delhi. pp.70-72(1967)

14.Patel, K.V and Parameswaran M, Effects of heat treatment on lipid degradation in bajra flour during storage. Journal of Food Science and Technology 29(1):51-52 (1992).

15.Rooney, L. W,Sorghum and pearl millet lipids. Cereal Chem. 55:584 (1978).

16.Thiam, A. A., Drapron, R., and Richarch-Molard, D, Causes d'alteration des farines de mil et de sorgh. Ann. Technol. Agric. 25:253(1976). 